\title{
Da utilização do preservativo masculino à prevenção de DST/aids
}

\author{
From condom use to prevention of STD/AIDS
}

Valéria Silvana Faganello M adureira ${ }^{1}$

M ercedes Trentini ${ }^{2}$

${ }^{1}$ Universidade do Contestado. Rua Victor Sopelsa 3000, Bairro Salete. 89700-000 Concórdia SC. val@uncnet.br

${ }^{2}$ Universidade Federal de Santa Catarina.
Abstract M en's attitudes were investigated re garding the condom use in heterosexual intercourse. The study was characterized as secondary analysis of part of wider research aiming to understand power in heterosexual intercourse from the man's perspective. The secondary analysis proposed to analyze research data obtained and analyzed in a previous study to answer questions other than those contained in the original study. Ten men from west Santa Catarina took part in theoriginal study; for the present study the data of participant identification, thegroup discussion and the interview of the original study were used. The data analysis comprised reading all the information, extracting common reports, grouping codes according to their nature; category formation. The results showed men's attitudes in the following categories: condom only to prevent pregnancy; condom with the wife denotes cheating; the condom should be used when 'out'; I have never used a condom; safe sex. In STD/AIDS prevention, aspects linked to beliefs, myths, health stereotypes and the characteristics of man-woman relationships become entwined.

Key words Sexually transmitted diseases, Condom, Sexual intercourse, Prevention, M en
Resumo 0 objetivo deste estudo foi analisar as atitudes de homens referentes ao uso do preservativo masculino nas relações heterossexuais e se caracteriza como análise secundária de partedeuma pesquisa de maior amplitude que teve o propósito de compreender o poder nas relações de casais heterossexuais a partir da perspectiva do homem. A análise secundária propõe examinar dados de pesquisa obtidos eanalisados num estudo prévio para responder questões diferentes das do estudo original. Do estudo original participaram dez homens do oestedeSanta Catarina. Para o presenteestudo, foram usados os dados deidentificação dos participantes, bem como dados gerados nas discussões do grupo edas entrevistas realizadas no estudo original. A análise dos dados consistiu em leitura de todas as informações; extração dos rel atos comuns; agrupamento dos códigos de acordo com sua natureza e formação de categorias. Os resultados mostraram atitudes dos homens em relação às seguintes categorias: preservativo somente para evitar gravidez; preservativo com a esposa denuncia traição; o preservativo deve ser usado "fora de casa"; nunca usei preservativo; sexo seguro. Na prevenção de DST/aids, emaranham-se aspectos vinculadosàs crenças, aos mitos, aos ester eótipos em saúde e às características dos relacionamentos homemmulher.

Palavras-chave U so do preservativo, Relações sexuais, Homens, Prevenção, DST/aids 
Introdução

$\mathrm{Na}$ vida sexual e reprodutiva, o preservativo masculino é um recurso disponível a homens e mulheres que aten de à dupla função de proteção contra a gravidez e contra doenças sexualmente transmissíveis (DST), dentre as quais a aids. M esmo assim, são comuns as resistências explícitas ou veladas ao seu uso tanto por parte de homens como de mulheres.

Da mesma maneira, os próprios profissionais da saúde podem não o indicar em função de vários elementos como, por exemplo, a visão de que a gravidez acontece no corpo feminino, 0 que torna a contracepção um encargo das muIheres e a compreensão de que o preservativo é um recurso masculino a ser recomendado para homens. Aqui, é importante considerar a cisão comumente observada nos programas de saúde, que fragmenta a atuação profissional e desvincula a contracepção da prevenção de DST/aids, embora ambas integrem o campo da saúde se xual e reprodutiva.

Além disso, a política de controle populacional em voga no Brasil em passado recente privilegiava métodos direcionados à mulher que dispensavam a participação masculina, o que resultou em declínio nas taxas de fecundidade e na marginalização dos métodos de barreira (como o preservativo), que dependiam da colaboração do homem. Disso derivou o que Barbosa denomina de cultura contraceptiva, ou seja, idéias e práticas adversas às mu danças de comportamento sexual que a epidemia de aids solicita.

Entretanto, a eclosão dessa epidemia nas dé cadas de 1980 e 1990 evidenciou o uso do preservativo como forma de proteção mútua dos parceiros, solicitando a inclusão do homem nas de cisões da vida sexual e reprodutiva do casal e valorizando a participação dele. 0 comportamento sexual do homem foi repentinamente colocado no centro das aten ções, acompanhado de grande valorização do preservativo no controle da epidemia, apesar da longa prática de focalização na mulher e das crenças relacionadas ao preservativo, que contribuíam para que o seu uso fosse dispensado.

A naturalização do papel da mulher na contracepção e da pouca participação masculina na mesma, aliada à resistência disseminada ao uso do preservativo delineava um quadro nada alentador para a prevenção de DST/aids, agravado pela cisão entre a atenção ao planejamento familiar (especialmente para mulheres) ea atenção as DST (especialmente para homens e prostitutas).
Respostas a essa situação incluíram um vasto investimento público em iniciativas de prevenção por todo o território nacional que proliferaram a partir da na década de 1990 enas quais a promoção do uso do preservativo ocupava posição central. É importante, entretanto, não supor que o quadro descrito esteja associado à falta de informação; ao contrário, observa-se que ela existe, mas que não se traduz em aplicação prática para prevenção, o que é coerente com 0 observado por Monteiro². Dessa situação, surgiu a necessidade de conhecer o modo de pensar e agir de homens heterossexuais em relação ao uso do preservativo. Para isso, foi delineado este estudo, que se propõe estudar as atitudes de homens do oeste de Santa Catarina sobre o uso do preservativo masculino em relações conjugais e extraconjugais.

\section{M etodologia}

Este estudo se caracteriza como análise secundária de um corte da tese de doutorado desenvolvida anteriormente, que teve o propósito de compreender o poder nas relações de casais heterossexuais a partir da perspectiva do homem ${ }^{3}$. Das informações obtidas no estudo original, apenas as relacionadas ao uso do preservativo nas relações heterossexuais foram analisadas no presente estudo.

O método de análise secundária propõe analisar dados depesquisa obtidos e analisados num estudo prévio, o que pode ser feito pelo pesquisador do estudo original ou por outros. Este mé todo é utilizado para responder questões diferentes daquelas estabelecidas no estudo original, ou então, para responder às mesmas sob outro ponto de vista e/ou utilizando outros métodos e técnicas de análise ou outro referencial ${ }^{4}$.

Thorne ${ }^{5}$ indica cinco modalidades de investigação em que uma análise secundária pode ser feita: 1) expansão analítica: o investigador faz uso adicional da base de dados original para responder perguntas em nível diferente de análise do estudo original ou para formular novas questões; 2 ) interpretação retrospectiva na qual a base de dados se amplia para considerar novas questões que foram planejadas, mas não examinadas com profundidade no estudo original; 3) indução de apoio: os pesquisadores se fundamentam melhor no desenvolvimento da teoria do que no compromisso com o fenômeno estudado, podem aplicar métodosindutivos de análise detexto, tais como a investigação hermenêutica, ao 
conjunto de dados existentes; 4) amostra ampliada, com a qual se pode gerar teorias mais ampliadas comparando várias bases de dados distintas eteoricamente representativas; 5 ) intervalidação na qual os dados originais são ampliados para confirmar ou descartar resultados e sugerir padrões além do poder da amostra estudada no estudo original. 0 presente estudo se enquadra nas modalidades descritas nos números 1 e 2 .

Do estudo original, participaram dez homens do oeste catarinense que viviam relações afetivosexuais duradouras, conviviam com suas parceiras e tinham filhos. A idade dos participantes variou de 24 a 45 anos e o tempo de casamento de dois a 23 anos. Dos dez participantes, dois tinham formação superior, sete, formação média e um, formação básica. 0 número de filhos variou de um a dois. As informações foram obtidas em discussões de grupo (seis encontros) e entrevistas individuais (duas com cada homem), tendo a pesquisa convergente-assistencial ${ }^{6} \mathrm{como}$ referencial metodológico, o que permitiu ao investigador envolver os participantes num processo de educação em saúde e coletar dados para pesquisa, utilizando-se de reflexão e discussão em grupo.

Para este estudo, foram disponibilizados os dados deidentificação dos participantes, astranscrições digitadas dasinformações obtidas durante as discussões no grupo e nas entrevistas. Do montante dos dados do estudo original, foram extraídos os que revelaram atitudes dos participantes em relação ao uso do preservativo masculino nas relações conjugais. A análise dos dados, para este estudo, incluiu leitura de todas as informações obtidas sobre 0 uso do preservativo; extração dos relatos comuns (códigos); agrupamento dos códigos de acordo com sua natureza e formação de categorias.

Os aspectos éticos preconizados pela Resolução CN S nº 196/96 foram integralmente atendidos no desenvolvimento do estudo original e o projeto foi aprovado pelo Comitê de Ética em Pesquisa da UFSC.

\section{Resultadosediscussão}

Os participantes deste estudo mostraram atitudes diversificadas em relação ao uso do preservativo masculino nas relações conjugais e extraconjugais, como mostram as categorias a seguir.
Preservativo somente para evitar gravidez

. Eu uso preservativo nos intervalos do comprimido.

. U so mais para evitar filho, porque pelas doenças, pela aids, eu sei que não pego, porque não sou desses que sai por aí dando sopa para todo mundo.

. Não há necessidade de usar porque eu não tenho nenhuma aventura externa.

. 90 a 95\% dos homens só usam em casa se a mulher não pode tomar pílula ou se tem algum problema que precisa usar.

- Acho que até a mulher tem dificuldade para aceitar o preservativo se ela for normal e puder tomar comprimido.

Preservativo com a esposa

põe em dúvida a confiança

. É difícil para um homem com muitos anos de casado começar a usar camisinha. 0 que ele diz?A esposa vai pensar que ele tem alguma coisa fora de casa ou que ele desconfia dela.

. Pode até ser possível se tiver um entendimento; aí vem a importância da confiança e do diálogo no casal. Eu confio na minha mulher e ela confia em mim porque se não tiver esta confiança, não tem vida de casal.

- Você confia sempre com uma interrogação, porquea gente não está semprejunto e eu não sei o que passa pela cabeça dela.

No relacionamento conjugal, o uso do preservativo podeser intermitente, coincidindo com os intervalos no uso do anticoncepcional oral (AO) ou contínuo, motivado pela impossibilidade de a mulher utilizar $\mathrm{AO}$. Todas as variações possíveis do uso/não uso do preservativo indicadas nos discursos têm como pano de fundo a preven ção da gravidez. Situação semelhante foi identificada por Hernandéz-Girón et al. ${ }^{7}$ em estudo na cidade do M éxico, no qual homens com parceiras regulares indicaram o planejamento da família $(86,7 \%)$ e a prevenção de DST $(12,1 \%)$ como principais motivos para a utilização do preservativo na última relação sexual.

No Brasil, Kalckmann ${ }^{8}$ observou que o preservativo era utilizado esporadicamente e a maioria dos homens participantes do estudo tinha como objetivo prevenir gravidez, especialmente quando a mulher não podia usar AO. Desses homens, poucos usavam contínua e sistematicamente o preservativo. 
A prevalência da preocupação com prevenção de gravidez sobre a preocupação com prevenção de DST/aids encontrada nos estudos mencionados converge com o identificado neste grupo de homens, os quais também têm a prevenção de gravidez como foco principal do uso do preservativo no seu relacionamento conjugal.

Os discursos indicam também que os homens consideram difícil introduzir o preservativo no relacionamento conjugal, o queestá relacionado aos significados que o mesmo evoca: símbolo de infidelidade e de desconfiança. Propô-lo significa pôr sua própria fidelidade em dúvida aos ol hos da esposa, o que colocaria em risco o convívio.

A confiança na parceira, por sua vez, forma uma díade ambivalente com a desconfiança quando se refere à fideli dade dela na relação. $\mathrm{Da}$ maneira como écolocada, essa confiança faz parte de uma aposta do homem na relação conjugal, a qual traz alguns riscos, pois ele só pode ter certeza sobre seu próprio comportamento.

Em estudo desenvolvido com 27 homens de camadas populares na cidade do Rio de Janeiro, Almeida ${ }^{9}$ encontrou uma estreita relação entreo não uso do preservativo no relacionamento de casal ea fidelidade. N esse estudo, al guns homens relataram que, com o casamento, estabeleceram uma relação de exclusividade efizeram um pacto de fidelidade com as esposas, o que leva ao uso do preservativo em situações especiais e a considerá-lo como provisório no casamento.

Os discursos relativos à vida afetivo-sexual no presente estudo apontam a fidelidade como um princípio no relacionamento conjugal queinfluencia diretamentea confiança mútua entrehomem e mulher. Assim, a proposição de uso regular do preservativo em um relacionamento em que o mesmo não era usado pode abalar a confiança existente entre os parceiros por questionar a fidelidade deum ou deambos, o que fica claro na afirmação "a esposa vai pensar que ele tem alguma coisa fora de casa ou que ele desconfia dela".

Sobre a associação entre a proposição de uso do preservativo em um casal que já utiliza outro método contraceptivo e a infidelidade/desconfiança, Silva ${ }^{10}$ afirma que o preservativo éconsiderado elemento estranho na situação conjugal, mesmo para contracepção, ea introdução de seu uso poderia abalar a confiança depositada na(o) parceira(o). 0 significado de "confissão de parcerias clandestinas e arriscadas" ${ }^{11}$ atribuído por homens e mulheres ao preservativo joga importante papel nesse estado de coisas, bem como a associação do preservativo com sexo ilícito ${ }^{12}$.
A vinculação entre uso do preservativo, fidelidade/infidelidade e confiança/desconfiança no casal foi também encontrada por Fonseca ${ }^{13} \mathrm{em}$ estudo com adolescentes, no qual um número considerável de jovens relata o uso do preservativo apenas na primeira relação sexual com uma (um) parceira(o), dispensando-o depois disso pela confiança que tem nela(e). Esses dados, encontrados em indivíduos que nasceram depois da eclosão da epidemia de aids, quando uma sé rie de ações de prevenção, diagnóstico e tratamento já faziam parte do cotidiano da atenção em saúde, suscitam questionamentos que se voltam não para o conhecimento sobre DST/aids e sexualidade, mas para as relações entre homens e mulheres heterossexuais e para suas características de poder e gênero.

A comunicação entre homem e mulher, bem como as habilidades de cada um na mesma, são essenciais nas estratégias de negociação do uso do preservativo. Em estudo sobre esta questão, Lam et al. ${ }^{14}$ perceberam diferenças étnicas nas características de utilização de estratégias verbais e não verbais na negociação sexual, às quais se aliam diferenciais de gênero.

Noar et al..$^{15}$ também consideram questões relativas ao gênero na negociação sexual e comentam que, devido ao duplo padrão sexual que permite maior liberdade ao homem do que à mulher e às diferenças nas relações de poder, poder-se-ia crer que os homens poderiam aumentar as taxas de uso de preservativo nas relações sexuais. Entretanto, isto pode não ocorrer se o homem não tiver habilidade e competência para comunicar, negociar eafirmar seu desejo de usar o preservativo. Para esses autores, a assertividade sexual e a habilidade para afirmar seu desejo de usar preservativo podem ser cruciais para um comportamento sexual mais seguro, 0 que volta o foco de aten ção para a comunicação entre o casal.

Entretanto, mesmo considerando-se as habilidades de comunicação de cada um ea qualidade da relação existente entre os parceiros, a idéia de "negociar" pode não ser bem aceita no relacionamento conjugal pel ossignificados queevoca eque parecem incoerentes com uma relação pautada por princípios de amor e fidelidade. "N egociar" relaciona-se, em geral, à idéia de comércio em que bens/valores são comprados, vendidos ou trocados. A transposição dessa idéia para o relacionamento conjugal, especialmente para o relacionamento sexual do casal, pode colocar em um mesmo nível estarelação socialmenteaprovada eaquelas consideradas ilícitas e marginalizadas. 
Segundo Barbosa ${ }^{1}$, a negociação sempre foi associada à prostituição eà promiscuidade, condições muito próximas da doença e da degradação. Com o crescimento da epidemia de aids, a negociação sexual passou a ser desejável evalorizada positivamente por sua vinculação com a preservação da saúde. Entretanto, mesmo com a tentativa de ressignificação da palavra negociação, a associação com compra e venda de algo continua presentee, embora o sexo no casal possa ser utilizado como um valor de troca, a "negociação" podenão se dar racionalmentenuma conversa, conforme também ressalta Villela ${ }^{11}$. Nas relações conjugais, a palavra "negociação" poderia ser transmutada em diálogo e acordo entre homem e mulher, pois embora esses termos impliquem a necessidade de negociar, não têm 0 peso moral geralmente associado a esta palavra. Ao contrário, dialogar e chegar a um acordo subentende cumplicidade, respeito, consideração pelo outro.

\section{O preservativo deveser usado "fora decasa"}

- Sempre usei preservativo fora de casa.

- Eu usei cami sinha com todas as mulheres com quem tive relação depois do meu casamento; não me arrisquei em nenhum caso.N unca gostei, mas nunca deixei de usar.

- Acho que éum pouco desconfortável, mas tem que usar se sair.

. Até pode sair por aí, mas tem que se cuidar, porque se a mulher engravidar, ele vai ter proble ma em casa com a esposa, com a família. Se ficar provado que o filho é seu, tem de pagar ou sofrer penalizações.

. E também tem as doenças!

\section{Nunca usei preservativo}

- Eu nunca usei camisinha, coisa que deveria. $M$ as na hora, você vêa pessoa e pensa que ela não tem nada.

- U ma relação fora de casa acontece de repente, não é premeditada. Às vezes a oportunidade surge, o cara não tem preservativo junto e 0 trem pode passar uma vez só!

- Você vai sair com uma mulher, rola alguma coisa e na hora do vamos ver, se você mostrar a camisinha pra ela, perde todo o clima!

. U m cara que trabalha comigo entrou no clima com uma mulher; quando chegou na hora, ele não tinha preservativo e transou para não passar vergonha.

- Naquela hora, a pessoa quer sentir prazer e não quer pensar se tem que colocar ou não a camisinha ou em qualquer outra coisa.

. Eu duvido quea pessoa se cuide quando chega na hora ' $\mathrm{H}$ ' mesmo que tenha instrução! Isso eu falo por mim também.

Às vezes uso, às vezes não uso

- A moça era do interior etinha saído com dois ou três. No começo eu tinha medo, mas como ela teve poucos parceiros, eu não usava preservativo com ela. Depois ela começou a tomar pílula e eu ficava mais tranqüilo.

. No começo, eu usava preservativo, mas como parecia que ela ficava só comigo, eu propus: "vamos transar sem preservativo".

. Em alguns casos que duravam mais, sempre dizia pra ela se cuidar para não engravidar.

. Eu às vezesuso, às vezesnão uso eémais pelas doenças, porque numa relação fora de casa, o homem não se preocupa com gravidez. Pra ele tanto faz ea conseqüência ésó da mulher. Se engravidar, vai arcar com a gravidez, carregar o filho no colo e o homem some! Pode dar um dinheiro de vez em quando, mas a conseqüência maior é dela.

Nas relações extraconjugais, o preservativo pode ser usado em todas as relações como forma de evitar riscos ao relacionamento conjugal; nunca ser usado nessas relações, em razão do caráter não premeditado delas, aliado a outros motivos; ser restrito aos primeiros encontros sexuais com uma parceira, sendo dispensado após "avaliação" da história sexual dela e de demonstrações que 0 homem considere indicadoras de fidelidade; ser dispensado desde o início se a parceira demonstrar pouca experiência sexual; ser dispensado quando o homem crê que a mulher "cuida" para não engravidar, mesmo sem a certeza dequeela utiliza algum método contraceptivo.

No que se refere a homens com múltiplas parceiras, Hernandéz-Girón et al. ${ }^{7}$ revelam que, em estudo na cidade do M éxico, os motivos indicados para o uso do preservativo foram prevenção de DST $(87,5 \%)$ e planejamento familiar $(9,2 \%)$. Já no caso dos homens participantes deste estudo, as indicações de uso do preservativo em todas as relações extraconjugais presentes nos discursos têm a dupla função de prevenção de gravidez e de DST/aids, embora a preocupação central seja com a gravidez.

A intenção subjacentea essa forma de agir éa manutenção dessas relações em segredo, evitando que sejam denunciadas por gravidez ou por doenças, o que colocaria em risco a manutenção 
da família, altamente valorizada pelo homem. Usar preservativo em relações extraconjugais é uma maneira de manter o mundo de "fora" e as experiências nele vividas afastadas do "mundo de casa".

Fica evidente em alguns discursos a pouca ou nenhuma preocupação com a prevenção de gravidez em relações extraconjugais, embora a contracepção seja preocupação central no relacionamento conjugal. Parece que, aqui, o cumprimento do mandato de provedor do homem na família é decisivo ea atenção dada à prevenção de gravidez no relacionamento conjugal visa adequar 0 número de filhos à sua capacidade de provimento, para que possa sustentar a família proporcionando aos filhos boas condições de vida e educação, o que parece ocorrer mesmo quando a esposa compartilha a manutenção do lar e da família.

Assim, é possível vislumbrar uma relação existente entre participação nas decisões reprodutivas, capacidade de provimento e tipo de relacionamento. Nesta forma de pensar, épossível acreditar que há uma maior preocupação do homem e um maior envolvimento dele na contracepção dentro do relacionamento conjugal, por ter a responsabilidade social de manutenção da família, e o tamanho dela deve ser adequado à sua capacidade de provimento.

$\mathrm{N}$ as relações extraconjugais ocasionais isso não ocorre, o quejustificaria a responsabilização da mulher pela prevenção da gravidez, embora existam também situações nas quais o homem toma a iniciativa contraceptiva usando o preservativo como forma de evitar prejuízos (inclusive financeiros) à sua família.

Analisando os dados preliminares de um estudo desenvolvido com 84 homens trabalhadores de uma metalúrgica de São Paulo, Arilha ${ }^{16}$ destaca que, para eles, a preocupação com a reprodução não é construída na relação estabelecida com seu corpo, mas no contexto social. Essas afirmações permitem compreender a vinculação entre 0 envolvimento deles nas decisões reprodutivas e seus deveres para com a família, que remetem a uma concepção de homem, na qual a responsabilidade demonstrada na manutenção desua família ( não somenteem termosfinanceiros) o aproxima do ideal de homem almejado e o diferencia dos demais. Ao mesmo tempo, permite perceber os motivos que o levam a ter pouca ou nenhuma preocupação com a prevenção de gravidez em relações extraconjugais.

Esses aspectos dão uma idéia do longo caminho ainda por percorrer no controle da epidemia, na prevenção de novos casos, o que está diretamente envolvido com as relações entrehomens emulheres, mostrando queépreciso adentrar o terreno das questões relacionadas com poder e gênero envolvidas no viver de ambos.

Os discursos relativos a relações extraconjugais indicam que o uso do preservativo em todas as relações dessa natureza éuma maneira de proteger a família, que correria o risco de desfazer-se ou de, pelo menos, ter a harmonia do convívio abalada caso fossem denunciadas. 0 uso do preservativo em relações "fora" de casa sugere também a figura da esposa como mulher de confiança, que dá segurança em contraponto à outra, perigosa, tanto para transmitir doenças como para engravidar intencionalmente à revelia do homem.

Essa situação reforça a existência de uma duplicidade quelocaliza o homem entre dois mundos: o de sua família, de casa, dos afetos, seguro, onde ele assume uma imagem de homem compatível com aqueleideal almejado, eo mundo de "fora", da rua, das relações mais impessoais, perigoso, onde procura preservar uma imagem que enfatiza o caráter indomável da sexualidademasculina ea prontidão para o sexo, quetorna difícil recusar uma oportunidade de manter uma relação sexual sob pena de ter sua virilidade questionada. 0 trânsito entre esses dois mundos exige atenção permanente, bem como certa dose de escolha e comedimento no sentido de mantê-los ignorantes um do outro.

Nas relações extraconjugais, há também o discurso que indica o não uso do preservativo, evidenciando aspectos relacionados com uma certa manei ra de ser homem que reforça os estereótipos de masculinidade. A referência feita ao caráter não premeditado dessas relações atua reforçando a prontidão para o sexo, vinculada a uma animalidade "natural" do homem. Também é ressaltado o efeito negativo à imagem de homem provocado pela recusa à possibilidade de manter uma relação sexual, de tal forma que é imperativo não desperdiçar uma oportunidade. De acordo com esse pensar, é legítimo manter uma relação sexual desprotegida, mesmo sabendo-a arriscada, para não se expor à possibilidade de ter sua masculinidade questionada.

"Perder o clima" em um encontro sexual é um risco oferecido pelo preservativo esugere que as relações acontecem em um crescendo, onde a passagem de beijos e carícias para a penetração ocorre "naturalmente" e não deve sofrer interferências de qualquer tipo. A interrupção da interação homem-mulher para propor o uso do preservativo expõe o homem ao risco de perder a 
oportunidade de manter uma relação sexual, o que seria incompatível com uma determinada maneira de ser homem.

Em estudo sobre o poder no casal, sexualidade e reprodução, realizado com mulheres de Santiago (Chile), Valdés et al. ${ }^{17}$ afirmam que, de acordo com as participantes, o ritual de aproximação eaceitação/recusa entre homem emulher nem sempre utiliza linguagem verbal. Ao contrário, trata-se de carícias, gestos/sinais e de determinadas respostas que não são necessariamente verbais. É um jogo no qual a verbalização em alguns momentos também é importante.

Essas considerações aproximam-se daquilo que os homens participantes deste estudo falaram sobre as relações extraconjugais, nas quais o desenrolar do encontro, ocasião em que a conversação parece não ocupar lugar de destaque, exclui a negociação (ou mesmo a menção) do uso do preservativo e sobre contracepção. Disso re sulta a dupla exposição a DST/aids e à gravidez.

A necessidade de não perder uma oportunidade está relacionada com a crença de que o homem está sempre disponível para o sexo, de forma que os encontros sexuais tendem a ser inesperados e não planejados. Há também a crença na existência de um instinto sexual masculino incontrolável, que dificulta a adoção de medidas de proteção. Além disso, o preservativo é considerado incômodo, o que contribui para que seu uso seja dispensado ${ }^{18}$.

Os discursos mostram o desejo de firmar-se frente aos outros como homem heterossexual não desperdiçando oportunidades sexuais, o que os leva a relações sexuais desprotegidas. Indicam também o risco de passar vergonha diante da mulher e de ser considerado "menos homem" ao recusar-se a manter uma relação sexual, o que está muito relacionado com a possibilidade de ser confundido com um homossexual. Esses elementos reforçam a norma socialmente imposta eaceita que destaca a prática sexual intensa ecom múltiplas parceiras como prova de virilidade ${ }^{19}$.

O não uso do preservativo em relações extraconjugais podeindicar a inexistência de qualquer conversação anterior que permita considerar a escolha do preservativo. Da mesma maneira, o uso de AO pela mulher étido como óbvio, posto que nada parece ser dito/feito no sentido de certificar-se sobre isso.

Outro elemento dos discursos indica a separação entre prazer e razão, a existência de uma incompatibilidade "natural" entre eles, que impede o homem de pensar naquilo que vai fazer no momento de uma relação sexual. A necessi- dade de uso do preservativo deixa de ser considerada porque demanda um exercício de racionalidade em um momento em que a busca pelo prazer é premente e responde ao desejo sexual, considerado irracional em si mesmo. Essa premência, aliada ao não planejamento desses encontros sexuais eà possibilidade de perda deuma oportunidade de manter relação sexual, impede que a situação seja racionalmente considerada a ponto de pensar no uso do preservativo.

A crença deque o preservativo determina uma redução do prazer sexual, provoca uma interrupção na interação homem-mulher para ser colocado eimpede o contato direto entre ambos também contribui para o não uso. De acordo com as discussões de grupo, a associação entre uso do preservativo eredução do prazer sexual é feita também por homens que nunca o utilizaram baseados na opinião de outros.

Outros estudo ${ }^{20-22}$ também relacionam o uso do preservativo com a redução do prazer e com a restrição do contato direto com a mulher. Além disso, acrescem o temor de "broxar", de ter uma performance ruim, o incômodo provocado pelo preservativo, o prejuízo por ele trazido à ereção e a opinião negativa da parceira como elementos que contribuem para restringir o uso do mesmo.

0 homem utiliza alguns indicativos para justificar o uso irregular do preservativo nas relações extraconjugais, dentre os quais s vida sexual da parceira avaliada como "pobre" pelo homem tanto no que se refere ao número de parceiros sexuais como à freqüência das relações. Para avaliar, leva em conta a história sexual relatada pela mulher e o desempenho sexual dela, analisados com base em demonstrações de timidez ou desenvoltura. Neste caso, o relato de poucos parceiros sexuais e demonstrações de pouca experiência sexual e de timidez parecem ser utilizados como indícios suficientemente fortes para dispensar o uso do preservativo.

0 preservativo masculino pode também ser dispensado quando a relação extraconjugal se prolonga, deixando de configurar-se como sexo ocasional. N essa situação, o principal argumento apontado para abandonar o preservativo é a fidelidade da mulher ao homem, avaliada a partir de indícios que sugerem que ela não "fica" com mais ninguém. Como esses indícios não foram claramente explicitados, é possível deduzir que a intuição do homem jogue um papel importante. A referência à fidelidade nas relações extraconjugais evidencia a fragilidade dos argumentos quea valorizam nas iniciativas de prevenção as DST/ aids. 
Sexo seguro

- Sexo cem por cento seguro não existe, mas existe prevenção. A camisinha é prevenção; conhecer bem a pessoa eter uma única parceira mesmo quando solteiro também é, mas nada garante.

Fidelidade pode evitar aids se os dois forem fiéis.

Eu acho que o importante é eu me gostar e se eu pensar assim, vou mecuidar. Aí eu acredito que o sexo seguro pode acontecer. Se eu gostar de mim, não vou ter medo de fazer fei o para a mulher; vou poder dizer não.

- U ma boa conversa também é importante, porque um pode cobrar do outro o uso do preservativo masculino ou feminino. Acho quetudo énegociável.

Os discursos acima apontam diferentes aspectos considerados pelos homens na articulação do uso do preservativo com prevenção e sexo seguro, bem como para as múltiplas facetas a considerar em cada um. Falando sobre comportamento sexual e prática de sexo seguro entre homens do município deSão Paulo, Vieira et al. ${ }^{22}$ levantam a possibilidade de uma tendência à monogamia seriada no comportamento dos homens estudados que, mesmo indicando uma parceria por vez, pode significar muitas ao longo do tempo. A expressão seriada pode ser utilizada também em relação à fidelidade, especialmente na maneira como foi expressa nos discursos aqui apresentados. Assim, poderia ser entendida como fidelidade seriada, que considera uma parceira extraconjugal por vez, embora implique a existência de muitas antecedendo esucedendo a relação atual. As possibilidades decontrair DST/aids são ampliadas, tornando mais vulneráveis o homem e as mulheres (a esposa e as outras).

Os discursos fazem referência também a conhecer a parceira. 0 está implicado nisso? Da maneira como essa questão é tratada pelos homens e concordando com Guerriero et al. ${ }^{20}$, 0 tempo de existência da relação não é central nessa questão, especial mente em setratando derelações ocasionais, nas quais os parceiros podem ter se conhecido há poucas horas ou poucos dias eter utilizado elementos como a aparência física e/ou a simpatia e/ou a alegria, os quais são relacionados com saúde embora sejam pouco confiáveis para essa avaliação.

O conhecer bem a pessoa como forma de prevenção não deveser interpretado como sinônimo de intimidade e longo tempo de convívio, mas considerada em um continuum de variantes que se estendem desde o vago conhecer a(o) outra(o) desde a infância, por residirem no mesmo bairro ou por estudarem juntos, porém sem maior contato pessoal, até o ponto máximo de intimidade ecumplicidade no convívio.

Em estudo desenvolvido com homens rurais da zona da mata pernambucana, Alves ${ }^{20}$ observou situação semelhante, com o uso do preservativo podendo ser dispensado quando a muIher é conhecida, o que indica que ela reside nas proximidades eque o homem não tem um compromisso com ela. Isso pode ocorrer também quando o homem avalia se a parceira está saudável utilizando sinais como o jeito de andar, secreção na calcinha ou com um certo tipo de toque nos genitais da mulher.

Diferentes estudos $9,24,25$ apontam o conhecer $\mathrm{a}(\mathrm{o})$ parceira(o) como um recurso amplamente utilizado na prevenção de DST/aids. Isso ocorre apesar dos diversos significados desse verbo, variáveis de acordo com a interpretação dada a ele. A este respeito, Almeida ${ }^{9}$ diz que, em relação às DST eà aids, al guns crêem que conseguem avaliar se podem ou não se arriscar tendo uma relação sexual fora do casamento a partir de indicativos como a higi ene da parceira e conhecendo a mulher.

M onteiro ${ }^{2}$ identificou uma lógica que relaciona o conhecido com proteção e o desconhecido com ameaça. Essa lógica está presente nos cuidados com a saúde e na prevenção da transmissão do HIV, de forma que as possibilidades de uso do preservativo aumentam nas relações sexuais com desconhecidos, de "fora" da casa do indivíduo e da comunidade na qual ele vive e mantém relações interpessoais mais próximas. N esses casos, a atenção está na prevenção de doenças e o preservativo é indispensável apenas quando o sexo é percebido como perigoso. N essa forma de pensar, amplia-se o número de possíveis parceiras consideradas conhecidas e seguras.

Todas essas variantes do conhecer trazem implicações diferentes para o trabalho de prevenção. A mesma interpretação pode ser dada ao ter uma única parceira, especialmente considerando-se a possibilidade de fidelidade seriada, o que resulta em muitas parcerias ao longo do tempo com relações sexuais desprotegidas.

Os discursos fazem referência também ao "gostar de si" como elemento importante para que o sexo seguro aconteça. N esse sentido, a percepção do que é ser homem exerce grande influência e o cuidado desi, compreendido como um trabalho continuamente exercido pelo homem sobresi próprio, conduzindo-se de maneira compatível com um código de conduta quetenha para 
si, assume posição central na prevenção de DST / aids e no sexo seguro.

\section{Consideraçõesfinais}

No relacionamento conjugal, o sexo seguro e a prevenção de doenças não estão diretamente ligados ao uso do preservativo, mas à confiança, à cumplicidade, à fidelidade, ao diálogo, ao companheirismo existente no casal eà qualidade da vida sexual. Assim, em casamento que contecom esses elementos, os parceiros ten dem a dispensar 0 uso do preservativo e a centralizar suas atenções na contracepção. Homem emulher firmam um pacto de confiança e fidelidade mútuas que deixa para ambos o compromisso de zelar pela manutenção e pelo fortalecimento da relação e da família.

A fragilidade do argumento da fidelidadeusado nasiniciativas deprevenção deDST/aids, especialmente nos relacionamentos conjugais, advém da desconfiança que fomenta entre os parceiros justamente pelo fato de estas iniciativas centrarem-se na exclusividade sexual. Assim colocado, 0 argumento aprofunda a vinculação das DST/ aids com relações ilícitas e vincula o preservativo masculino com a infidelidade. Da mesma maneira, estas iniciativas não consideram as diferentes possibilidades de interpretação da fidelidade.

Sobre o uso do preservativo e o sexo seguro, gostar de si próprio, valorizar-se eestar seguro de si possibilitam ao homem diferenciar-se dos demais, permitindo-Ihe valorizar menos as deman- das socioculturais dos modelos de masculinidade, que colocam a necessidade de contínua comprovação pública de uma heterossexualidade incontrolável, bem como adotar condutas que diminuam sua vulnerabilidade no campo sexual, como, por exemplo, recusar-se a manter uma relação sexual mesmo estando "no clima"; propor o uso do preservativo sem antecipar o risco de perder a parceira e dialogar com ela sobre a vida sexual, DST/aids e seu relacionamento de casal.

De acordo com o que foi até aqui discutido, depreende-se que o uso do preservativo nas relações conjugais e/ou extraconjugais não é uma questão de normatização cientificamente fundamentada de comportamentos. Ao campo dos saberes científicos na área de promoção da saúde e, especificamente, de prevenção de DST/aids, emaranham-se outros tantos aspectos vinculados às crenças, aos mitos, aos estereótipos em saúde, bem como aos saberes de cada um, às questões de gênero eàs características dos relacionamentos homem-mulher.

Todos esses elementos associados apontam para o equívoco de iniciativas de promoção de saúde e de prevenção de DST/aids tomadas a partir da perspectiva científica e universalizadas. Frenteà complexidade dos saberes científicos que avançam a cada dia, os viveres das pessoas em geral não são menos complexos, posto que se dão em ambientes, culturas, situações socioeconômicas, circunstâncias diversas (de gênero, de poder, entre outras). A complexidade desses viveres merece ser considerada em iniciativas de educação em saúde.

\section{Colaboradores}

VSF M adureira foi autora da pesquisa original e foi responsável pela discussão dos resultados, participou da concepção do artigo, da interpretação dos dados e da redação.

$M$ Trentini orientou o estudo original e foi responsável pela metodologia, participou da concepção do artigo e da redação. 


\section{Referências}

1. Barbosa RM. N egociação sexual ou sexo negociado? Gênero, sexualidade e poder em tempos de aids [tese]. Rio de Janeiro (RJ): UERJ; 1997.

2. Monteiro S. Prevenção ao HIV/aids: lições e dilemas. In: Goldenberg P, M arsilglia M G, Gomes MHA, organizadores. 0 clássico e o novo: tendências, objetos e abordagens em ciências sociais e saúde. Rio de Janeiro: Fiocruz; 2003.

3. Madureira VSF. A visão masculina nas relações de poder no casal heterossexual como subsídio para a educação em saúde na prevenção de DST/aids [tese]. Florianópolis (SC): UFSC; 2005.

4. Szabo V, Strang VR. Secondary analysis of qualitative data (methods of clinical inquiry). Adv Nurs Sci 1997; 20(2):66-69.

5. Thorne S. El análisis secundario en la investigación cualitativa: asuntos e implicaciones. In: M orse JM editores. Asuntos críticos en los métodos de investigación cualitativa. Medellín: Editoral Universidad de Antioquia; 2005.

6. Trentini M, Paim L. Pesquisa convergente-assistencial: um desenho que une o fazer e o pensar na prática assistencial em saúde-enfermagem. Florianópolis (SC): Insular; 2004.

7. Hernandéz-Girón C, Valdez AC, Quiterio-Trenado $M$, Peruga A, Hernandéz-Avila $M$. Caracteristicas de comportamiento sexual en hombres de la Ciudad de Mexico. Salud Publica Mex 1999; 41(2):95-100.

8. Kalckmann S. Incursões ao desconhecido: percepções de homens sobre a saúde reprodutiva e sexual. In: Arilha M, Unbehaum SG, M edrado B, organizadores. Homens e masculinidades: outras palavras. Rio de Janeiro: Editora 34; 2001.

9. Almeida CCL. Risco e saúde reprodutiva: a percepção dos homens de camadas populares. Cad Saúde Pública 2002; 18(3):797-805.

10. Silva CGM . 0 significado de fidelidade e as estraté gias para prevenção da aids entre homens casados. Rev. Saúde Pública 2002; 36(4):40-49.

11. Villela WV. Prevenção do HIV/aids, gênero e sexualidade: um desafio para os serviços de saúde. In Barbosa RM, Parker R, organizadores. Sexualidade pelo avesso: direitos, identidade e poder. Rio de Janeiro: Editora 34; 1999.

12. Hoffman V, Bolton R. Reasons for having sex and sexual risk-taking: a study of heterosexual male std clinic patients. Aids Care 1997; 9(3):1-14.

13. Fonseca AD. A concepção de sexualidade na vivência de jovens: bases para o cuidado de enfermagem [tese] Florianópolis (SC): UFSC; 2004.
14. Lam AG, Mak A, Lindsay PD, Russel S. What really works? An exploratory study of condom negotiation strategies. Aids Educ Prev 2004; 16(2):160-171.

15. Noar SM, M orokoff PJ, Redding CA. Sexual assertiveness in heterosexually active men: a test of three samples. Aids Educ Prev 2002; 14(4):330-342.

16. Arilha M. Homens, saúde reprodutiva e gênero: 0 desafio da inclusão. In: Giffin K, Costa SH, organizadores. Questões da saúde reprodutiva. Rio de Janeiro: Fiocruz; 1999

17. Valdés T, Benavente M C, Gysling J. El poder en la pareja, la sexualidad y la reproducción: mujeres de Santiago. Santiago: FLACSO; 1999.

18. Aguirre R, Güell P. Hacer-se hombres: la construcción de la masculinidad en los adolescentes y sus riesgos. OPS/OMS, 2002.

19. Villela WV. Gênero, saúde dos homens e masculinidades. Cien Saude Colet 2005; 10(1):29-32

20. Alves M FP. Sexualidade e prevenção de DST/aids: representações sociais de homens rurais de um município da zona da mata pernambucana, Brasil. Cad Saúde Pública 2003; 19(Supl 2):429-439.

21. Guerriero I, Ayres JR, Hearst N. M asculinidade e vulnerabilidade ao HIV de homens heterossexuais, São Paulo SP. Rev. Saúde Pública 2002; 36(4):50-60.

22. Olavarria J, Benavente C, M ellado P. M asculinidades populares: varones adultos jóvenes de Santiago. Santiago: FLACSO; 1998.

23. Vieira EM, Villela WV, Réa M F, Fernandes ME, Lemos FE, Ribeiro G. Alguns aspectos do comportamento sexual e prática de sexo seguro em homens do município de São Paulo. Cad Saúde Pública 2000;16(4):997-1009.

24. Buysse A, van Oost P. 'Appropriate' male and female safer sexual behaviour in heterosexual relationships. Aids Care 1997; 9(5):1-14.

25. Guimarães $C D$. "Mas eu conheço ele!": um método de prevenção do HIV/aids. In: Parker RG, Galvão J, organizadores. Quebrando o silêncio: mulheres e aids no Brasil. Rio de Janeiro: Relume-Dumará; 1996.

Artigo apresentado em 11/10/2006

Aprovado em 13/11/2006

Versão final apresentada em 11/01/2007 